\title{
DOCUMENTAÇÃO DE CONSERVAÇÃO DE ACERVOS EM PAPEL: A COLEÇÃO DE GRAVURAS ORIENTAIS PERTENCENTES AO MUSEU DE ARTE LEOPOLDO GOTUZZO
}

\author{
Pamela Pereira de Pereira - UFPel \\ pamelapereiracr@gmail.com \\ Claudia Fontoura Lacerda - UFPel \\ claufontouralacerda@gmail.com
}

\section{RESUMO}

Esta pesquisa tem como objeto de estudo o conjunto de gravuras orientais que fazem parte do acervo doado ao Museu de Arte Leopoldo Gotuzzo - MALG/UFPel, entre 2012 e 2016, por Luis Carlos Lessa Vinholes. As gravuras, que ainda se encontram em processo de inventário na instituição, são constituídas em suporte de papel, o que as tornam sensíveis à umidade relativa, à luz e à temperatura inadequadas. Este trabalho tem como objetivo realizar a catalogação e a preservação desta coleção de gravuras, através de pesquisa no arquivo do MALG, revisão bibliográfica, entrevista com o doador do acervo e consultoria com especialista em gravuras, além de análise do estado de conservação e a produção de fichas de identificação e diagnóstico desta coleção.

Palavras-Chave: Documentação; Conservação; Gravuras; Papel; Museu de Arte Leopoldo Gotuzzo.

\section{INTRODUÇÃO}

A presente pesquisa estuda a conservação das gravuras orientais, pertencentes ao acervo do Museu de Arte Leopoldo Gotuzzo - MALG/UFPel, que se juntaram recentemente ao patrimônio do museu através da doação do compositor, músico e poeta concretista $^{1}$ pelotense Luis Carlos Lessa Vinholes, cujo objetivo principal foi a preservação deste acervo, constituído de grande número de obras e composto de diversas

\footnotetext{
1 A poesia concretista é baseada em regras internas precisas que constroem sua estrutura e o tornam um objeto autônomo. Opõe-se às formas tradicionais do verso (lírico, subjetivo e discursivo) e valoriza o espaço gráfico como agente estruturador do poema. Apresenta o poema-objeto, construído por meio de recursos como a disposição não-linear dos vocábulos na página, o uso do espaço em branco como produtor de sentidos e a utilização de elementos visuais e sonoros, tendo como assunto principal a metalinguagem. CONCRETISMO. In: ENCICLOPÉDIA Itaú Cultural de Arte Brasileira. São Paulo: [s.n.]. Disponível em: $<$ http://enciclopedia.itaucultural.org.br/termo9594/concretismo>. Acesso em 14 set. 2016.
} 
tipologias e origens, no qual se insere a coleção de gravuras orientais com data provável do século XVII.

A finalidade desta pesquisa é a preservação deste acervo, através da documentação e da identificação do estado de conservação de cada uma das gravuras, resultando em fichas de diagnóstico, colaborando assim, no processo de inventário e de guarda na instituição detentora.

Neste sentido, para alcançar os objetivos propostos, a metodologia adotada foi a pesquisa no arquivo do MALG e a revisão bibliográfica referente à conservação e à restauração de bens culturais em suporte de papel, assim como às técnicas de gravura. Almejando ampliar o conhecimento em relação ao acervo doado, realizou-se entrevista com o doador do acervo, Luis Carlos Lessa Vinholes, e uma consultoria com a professora do Centro de Artes, Kelly Wendt, especialista nas técnicas de gravura.

Para identificar os materiais, técnicas, estado de conservação e prováveis causas de deterioração, a última etapa realizada foi a análise visual de cada uma das gravuras, executada com auxílio de lupa e acompanhamento de registro fotográfico. Em relação à análise do acervo, cabe salientar que devido à greve das três categorias ligadas à UFPel, esta não pôde ser desenvolvida na sua totalidade e se deu sobre $75 \%$ do acervo, número considerável que permitiu obter os resultados apresentados. Estes resultados, aliados à projetos futuros da pesquisadora, auxiliarão, além de estudos mais aprofundados sobre o tema, em concluir a análise total do acervo.

Como referencial teórico, esta pesquisa baseia-se em Clavaín (2009, p. 14) ao afirmar que a Conservação Preventiva engloba "acciones indiretas com el fin de retardar el deterioro y prevenir los riesgos de alteraciones, creando las condiciones óptimas de preservación compatibles com su uso social" e, também em Viñas (2010, p. 235) que compartilha dessa ideia acrescentando que a Conservação Preventiva compreende "todas aquellas operaciones de conservación que intervienen exclusivamente sobre el entorno del objeto que se pretende conservar $[\ldots] "$ ".

Sobre ataque de agentes biológicos em bens culturais em suporte de papel, apoiase em Callol (2013, p. 84) ao afirmar que a prevenção da biodeterioração "[...] inclui um conjunto de ações direcionadas a evitar o desenvolvimento dos agentes biológicos no ambiente e o ataque aos materiais constituintes dos acervos”. A autora ainda ressalta que em casos de infestação, o melhor é tentar controlá-los e minimizar seus efeitos. 
Em relação às técnicas de gravuras apoia-se em Kannaan (2014, p. 11-44) que expõe as principais existentes, dentre elas a xilogravura ${ }^{2}$, a calcogravura ${ }^{3}$, a litografia ${ }^{4}$ e a serigrafia ${ }^{5}$, especificando em detalhes e imagens os seus processos de reprodução.

Sobre a origem, a cultura e as tradições do povo oriental, assim como a originalidade e a criatividade expressas nas obras de grandes artistas orientais, apoia-se em Upjohn; Wingert; Mahler (1974, p. 257).

Para a identificação da técnica, do estilo, do período e dos autores da coleção de gravuras do MALG, esta pesquisa fundamenta-se também em catálogos sobre arte oriental pertencentes à Biblioteca do Instituto de Ciências Humanas (ICH) da UFPel, intitulados Fundação do Museu de Arte Mokiti Okada (M.O.A.) do Japão/Brasil (1953),

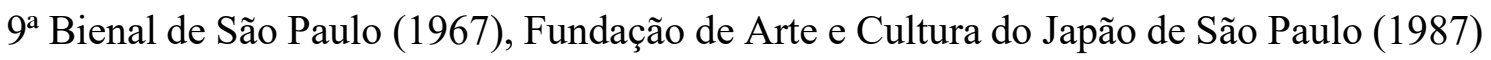
e Galeria de Arte do Museu do Trabalho de Porto Alegre (1998), os quais apresentam informações e ilustrações de gravuras orientais com os seus respectivos gravuristas.

Sobre a utilização de entrevista, está se baseou em questionário prévio e apoia-se em Alberti (2005, p. 22) ao considerar que "a entrevista de história oral permite também recuperar aquilo que não encontramos em documentos de outra natureza" e fundamentase também em Jovchelovitch; Bauer (2008, p. 92) que afirmam que "o contexto é dado e os acontecimentos são sequenciais”. As informações adquiridas, tanto na entrevista como

2 Técnica de gravura na qual se emprega como matriz uma placa de madeira, embora hoje em dia se utilize também o linóleo. As gravuras executadas com esta técnica apresentam um aspecto característico: as formas ou os motivos são separados por espaços em branco. PASCUAL, Eva. Conservar e Restaurar Papel. Lisboa: Editorial Estampa, 2006. p. 20.

3 Técnica que utiliza métodos diretos e indiretos para retirar da matriz do cobre, latão ou zinco, uma imagem com características peculiares a esse processo. Para métodos diretos, os instrumentos atuam sulcando a superfície, arrancando ou deslocando matéria. Nos métodos indiretos, são utilizados agentes intermediários, como ácidos mordentes, ceras e vernizes. KANAAN, Helena (org.). Manual de Gravura. Pelotas: Editora e Gráfica Universitária/UFPel, 2004. p. 25.

${ }^{4}$ Sistema de impressão onde o motivo a ser reproduzido é desenhado sobre uma matriz, tradicionalmente de pedra, embora atualmente possa ser metálica, com uma matéria gordurosa a lápis ou a pincel. Depois de terminar o desenho, a matriz é banhada em água e tingida. Com características semelhantes à do desenho convencional e a sua conservação é semelhante à das aquarelas. PASCUAL, op. cit., p. 22.

5 Sistema de impressão que utiliza como matriz uma moldura com uma tela de pano aberta em algumas zonas e fechada noutras constituindo a imagem a ser impressa. A tinta é arrastada e pressionada na tela de pano e é depositada sobre o suporte. Através da serigrafia é possível obter formas muito pormenorizadas e perfeccionistas, mas não permite meios-tons, apenas cores planas. PASCUAL, loc. cit. 
na consultoria, foram autorizadas para publicação, tornando-se apoios importantes no desenvolvimento da pesquisa.

Diante do valor significativo desta coleção de gravuras orientais do MALG, este trabalho pretende auxiliar no seu processo de preservação, através da criação de uma vasta documentação, que por sua vez será entregue a instituição.

\section{A COLEÇÃO DE GRAVURAS ORIENTAIS DO MUSEU DE ARTE LEOPOLDO GOTUZZO}

O Museu de Arte Leopoldo Gotuzzo (MALG) apresentado na Figura 01 foi inaugurado em 7 de novembro de 1986 e é vinculado ao Centro de Artes da Universidade Federal de Pelotas (UFPel), tendo como patrono o artista pelotense Leopoldo Gotuzzo (1887-1983) demonstrado na Figura 02.

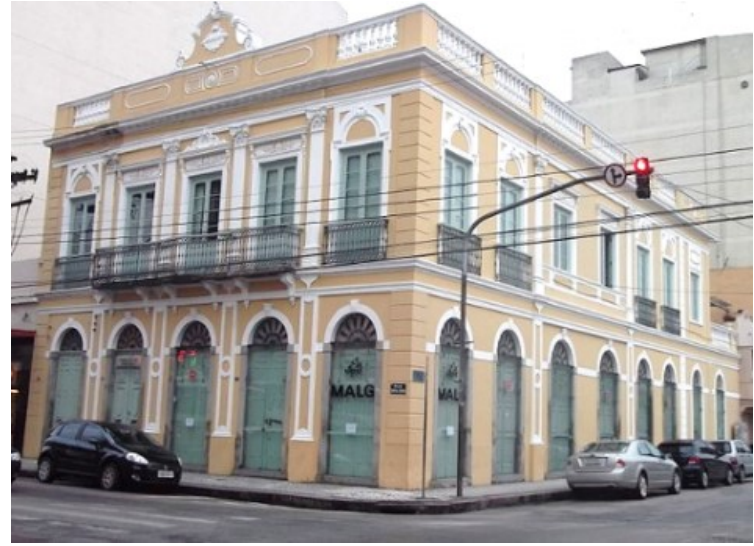

Figura 01 - Prédio do Museu de Arte Leopoldo Gotuzzo (MALG/UFPel).

Fonte: Fotografia da autora, 2016.

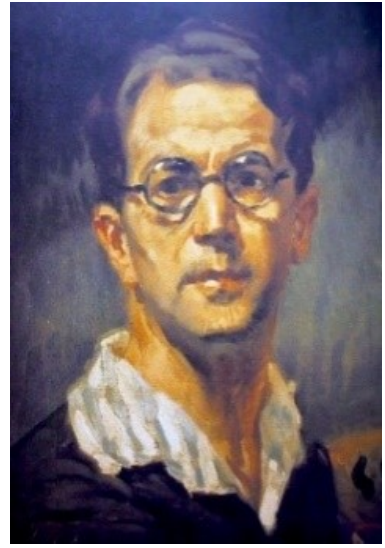

Figura 02 - Obra "Auto Retrato de Óculos" de autoria de Leopoldo Gotuzzo (1934). Fonte: Arquivo do Museu de Arte Leopoldo. Gotuzzo (MALG/UFPel), 2013.

O acervo da Instituição teve início a partir de duas doações de Leopoldo Gotuzzo: a primeira em 1955 e a segunda doação em 1983 através de carta testamentária, na qual se juntou ao acervo além de pinturas, objetos pessoais e mobiliários do artista (LACERDA, 2013, p. 23-24). Atualmente, o acervo é constituído em mais de 3.000 peças divididas em setes coleções: Coleção Leopoldo Gotuzzo, Coleção EBA, Coleção Dr. João Gomes de Mello, Coleção Faustino Trápaga, Coleção Século XX, Coleção Século XXI e a Coleção Luis Carlos Lessa Vinholes, doada entre os anos de 2012 e 2016, a qual ainda se encontra em processo de inventário no Museu e está constituída de grande variedade 
de tipologias como bengalas, cerâmicas, desenhos, esculturas, instrumentos musicais orientais, livros, louças, mapas e pinturas, entre os quais está incluído o conjunto de gravuras orientais, foco desta pesquisa.

Esta coleção de gravuras orientais, exemplificada na Figura 03, mostra os costumes e tradições orientais, são pertencentes ao início do século XVII e ao final do século XIX e representativas dos períodos Edo $^{6}$ (1625-1867) e Meiji ${ }^{7}$ (1868-1912).

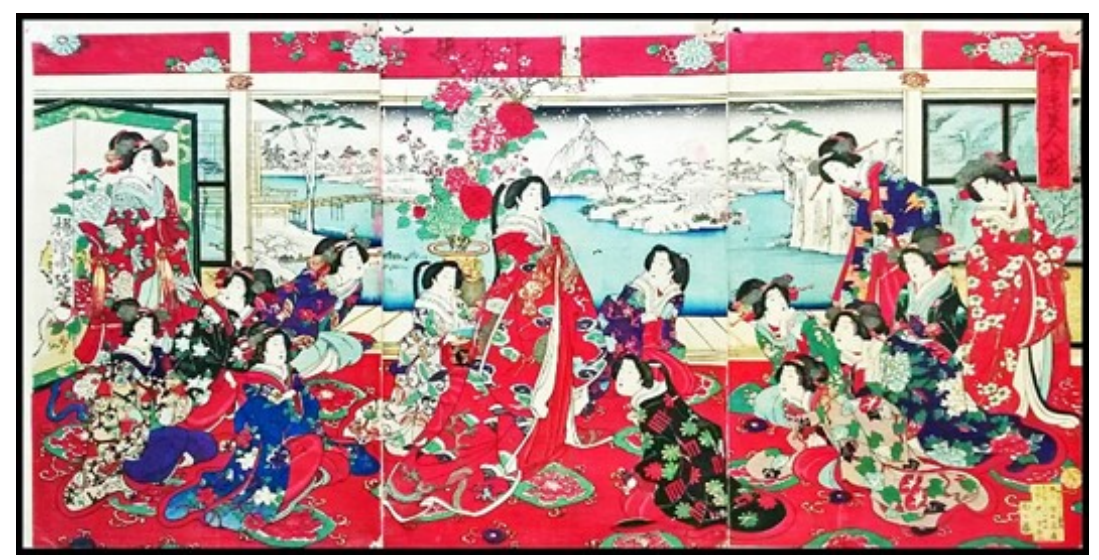

Figura 03 - Gravura Ukiyo-ê do século XIX doada ao MALG/UFPel, em 2014. Fonte: Fotografia da autora, 2016.

Pelo fato do acervo apresentar os primeiros indícios de degradação, e pensando também em aproximar os pelotenses da cultura oriental através de exposições no museu, o colecionador Luiz Carlos Lessa Vinholes (Figura 04), foi impulsionado a realizar a doação de sua coleção à Instituição, confiando assim o trabalho de conservação à equipe do MALG (VINHOLES, 2016).

6 Período da história do Japão, também conhecido como "A Idade da Paz Ininterrupta", onde proliferaram os samurais sem senhor, que com a desativação da guerra tiveram que se dedicar a outras tarefas, tornando-se responsáveis pelo desenvolvimento das artes, da escrita, da arte do chá, do teatro e da pintura. FARIA, Caroline. Período Edo. Info Escola - Navegando e Aprendendo. Disponível em: $<$ http://www.infoescola.com/japao/periodo-edo/>. Acesso em: 20 Dez.2016.

7 A Era Meiji foi um período de abertura da economia japonesa para o Ocidente. A industrialização e a modernização foram seus traços principais. As medidas mais importantes foram: a criação de infraestrutura; a instalação de indústrias de bens de produção; os grandes investimentos na educação para obter mão-de-obra qualificada; os investimentos feitos na indústria pelos grupos familiares; adoção do xintoísmo. CONRADO, Agrário. Japão - Era Meiji. Escrita Biblioteca Virtual de Escritores. São Paulo: Komedi, 2016. Disponível em: $<$ http://www.escrita.com.br/leitura.asp?Texto_ID=10697>. Acesso em: 20 Dez. 2016. 
A equipe do museu começou a realizar o processo de conservação desta coleção de gravuras orientais a partir de 2012.

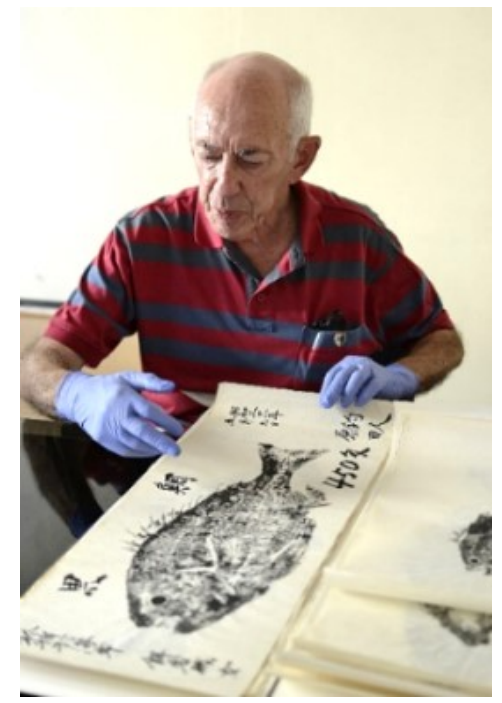

Figura 04 - Luis Carlos Lessa Vinholes apresentando uma de suas doações de gravuras a equipe do MALG.

Fonte: Arquivo do Museu de Arte Leopoldo Gotuzzo (MALG/UFPel), 2014.

Como característica do acervo, destaca-se a representatividade das tradições culturais do Oriente e o uso quase que em sua totalidade de papel artesanal japonês, chamado “washi”, para a impressão. De acordo com Craig (1987, p. 121) o washi é feito artesanalmente, um a um, por mãos habilidosas e que utilizam técnicas milenares, produzindo um papel único, com características peculiares e de grande resistência. Nesses suportes foram verificadas diferenças de gramatura, o que juntamente com as características expostas nas reproduções auxiliou na identificação do tipo de técnica de algumas gravuras.

As técnicas de gravuras encontradas nessa coleção foram, principalmente, a xilogravura Ukiyo-ê, a calcogravura e algumas litogravuras, assim como técnicas menos 
comuns de serem utilizadas, como Bugaku ${ }^{8}$, Gyotaku$^{9}$, Otsu-e ${ }^{10}$, Opúsculo $^{11}$ e Shunga ${ }^{12}$, representadas por ordem crescente nas Figuras 05, 06, 07 e 08.

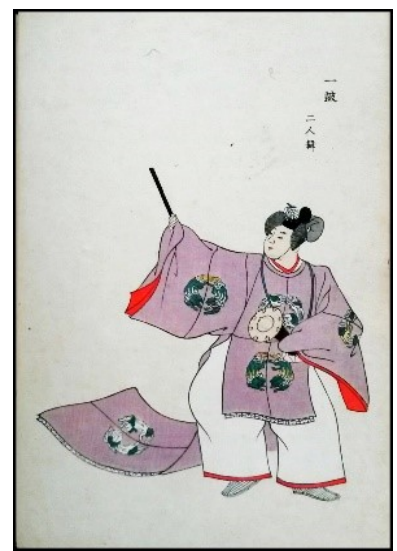

Figura 05 - Gravura página $n^{\circ} 40$ do Livro Bugaku - U Dança na Corte do Japão (1905).

Fonte: Fotografia da autora, 2016.

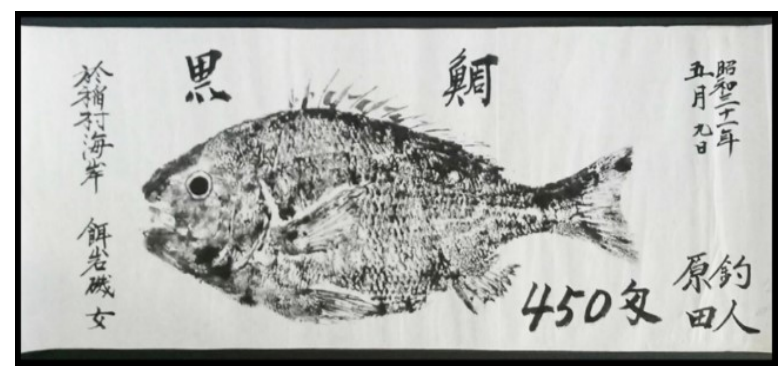

Figura 06 - Gravura Gyotaku Kurodaí ou Chinu de Harada (1956).

Fonte: Fotografia da autora, 2016.

8 É uma publicação que registra indumentárias usadas nas danças tradicionais praticadas em determinados eventos no Palácio Imperial, em Tóquio, e em algumas cerimônias dos principais templos xintoístas, destacando-se o Ise Jingu (Província de Ise), o Meiji Jingu (Tóquio) e a Kasuga Jinja (Nara). VINHOLES, Luis Carlos Lessa. 2016. Arquivo do Museu de Arte Leopoldo Gotuzzo/MALG. Universidade Federal de Pelotas/UFPel.

9 Palavra japonesa escrita com dois ideogramas, o primeiro "gyo" = peixe e o segundo "taku" = esfregar cuja prática teria começado no Período Edo (1603-1867). Tipo de gravura que utiliza o corpo de um peixe como matriz, onde os pescadores usando o "sumi-ê" (tinta da China), documentavam sobre folhas de "washi" (papel artesanal), os troféus das suas pescas, no qual o objetivo maior era o seu consumo. VINHOLES, Luis Carlos Lessa. 2014. Arquivo do Museu de Arte Leopoldo Gotuzzo/MALG. Universidade Federal de Pelotas/UFPel.

${ }^{10}$ São simples xilogravuras e pinturas sobre papel com temas budistas ou desenhos humorísticos que, no Período Edo, eram vendidos na cidade de Otsu. VINHOLES, Luis Carlos Lessa. 2014. Arquivo do Museu de Arte Leopoldo Gotuzzo/MALG. Universidade Federal de Pelotas/UFPel.

${ }^{11}$ Qualquer texto impresso que contém poucas páginas cujo teor pode ser artístico, literário, científico. DICIONÁRIO ONLINE DE PORTUGUÊS - DICIO. Opúsculo. Disponível em: $<$ https://www.dicio.com.br/opusculo/>. Acessado em: 03 Jan. 2017.

${ }^{12}$ Estampas de primavera geralmente, denominadas para as ilustrações e representações eróticas japonesas. FAHR-BECKER, Gabriele. Grabados Japoneses. Köln: Tashen, 2007. p. 193. 


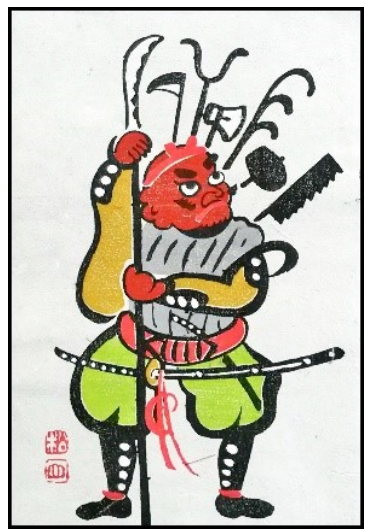

Figura 07 - Gravura Otsu-e Ben-kei de Takahashi Shouzan (sem datação).

Fonte: Fotografia da autora, 2016.

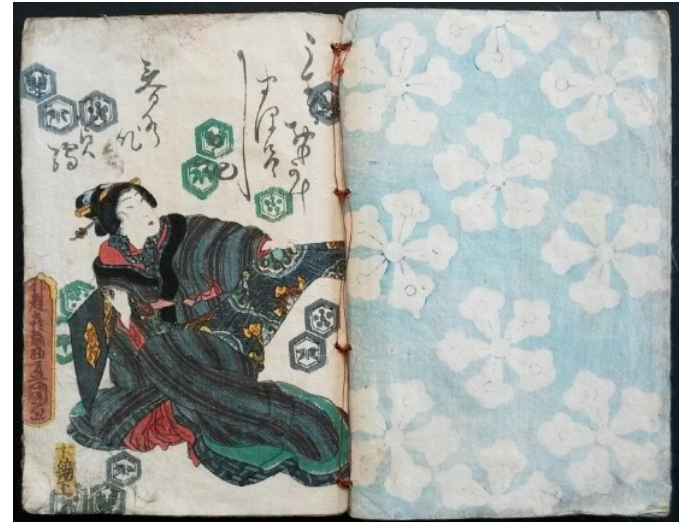

Figura 08 - Capa do Opúsculo com Shunga de Utagawa Kunisada (1865).

Fonte: Fotografia da autora, 2016.

Através dos referenciais bibliográficos encontrados sobre as tintas utilizadas em gravuras orientais, supõe-se que no acervo do MALG foi usado a tinta da China, denominada Sumi-ế $\hat{e}^{13}$, com cores neutras como o preto e o branco, conforme demonstrado na Figura 09, e cores vibrantes como vermelho, verde, amarelo, laranja, azul e roxo (Figura 10). Algumas delas apresentam traços simples, enquanto outras são bem mais elaboradas e, em algumas, não constam data nem autoria, como a gravura Ukiyo-ê (Figura 11).

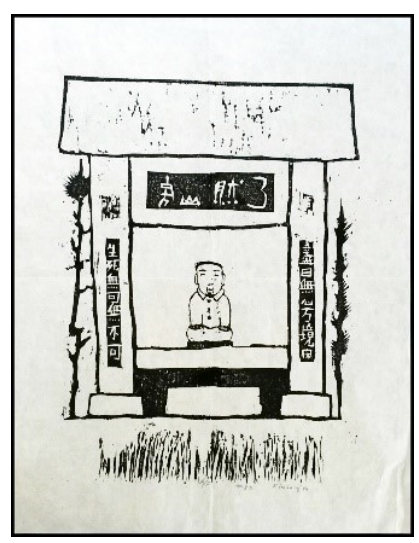

Figura 09 - Xilogravura \#82 de Kim Sang

$\mathrm{Yu}$ (sem datação) nas cores preto e branco.

Fonte: Fotografia da autora, 2016.

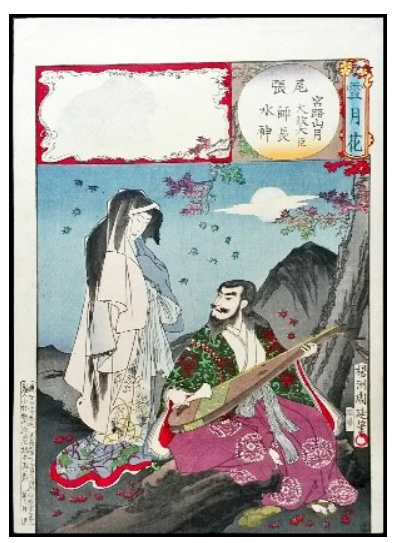

Figura 10 - Gravura Ukiyo-ê de 1884 nas cores azul, cinza, amarelo, verde, vermelho, roxo e preto.

Fonte: Fotografia da autora, 2016.

${ }^{13}$ É um corante feito com negro-de-fumo produzido com hidrocarbonetos a partir de fragmentos de fuligem de carbono ou derivados de árvores não-resinosas. A esses pigmentos negros são adicionados um aglutinante e água para formar a tinta chinesa tradicional, que foi utilizada pela primeira vez na China no III século a. C. PORTO, Julián Pérez; GARDEY, Ana. Definición de Tinta del China. In: Definición.de, 2014. Disponível em: <http://definicion.de/tintachina/>. Acesso em: 03 Jan. 2017. 


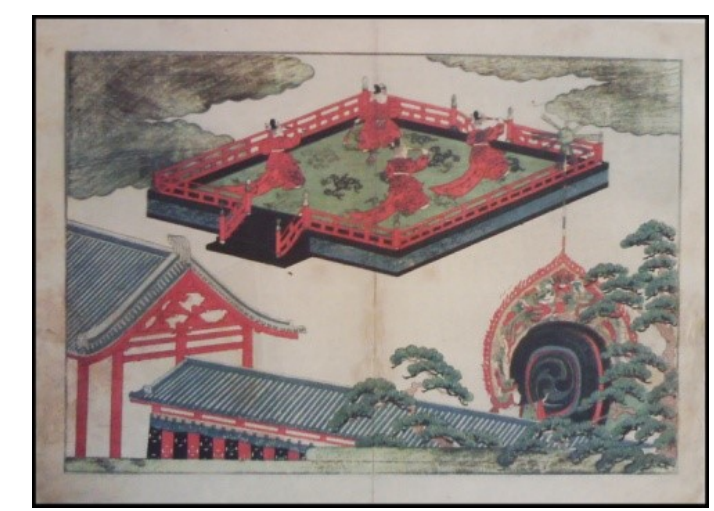

Figura 11 - Gravura Ukiyo-ê sem identificação, doada ao MALG, em 2014.

Fonte: Fotografia da autora, 2016.

Sobre a autoria das gravuras orientais do acervo, identificam-se Utagawa Toyokuni (1769-1825), criador das gravuras Ukiyo-ê, ilustrador de livros e pintor; Utagawa Kunimasa (1773-1810), especialista em retratos de atores de kabuki ${ }^{14}$; Utagawa Kunisada (1786-1864), ilustrador de livros e especialista em retratos femininos e de atores de kabuki; Utagawa Kuniyoshi (1797-1861), importante criador de gravuras coloridas, ilustrador e pintor Ukiyo-ê; e Toyohara Kunichika (1835-1900), talentoso colorista, reinventor do tríptico ${ }^{15}$ de teatro e hábil gravurista de retratos de atores (FAHR-BECKER, 2007, p. 197-198).

Destacam-se também os artistas: Kim Sang Yu (1926-2002), pintor e gravurista coreano (VINHOLES, 2014); Haku Maki (1924-2000), conhecido tanto pelo uso de caracteres chineses como pelo uso da técnica de bloco de cimento que permitia efeitos texturizados criando uma aparência tridimensional na gravura (TRETIAK, 2016); Hideo Yoshihara (1931-2007), membro da Associação de Gravuristas do Japão em 1959 (SHINKOKAI, 1967, p. 18) e, por último, a única artista mulher chamada Yuki Rei (1928-2003), que trabalhou com a antiga técnica da xilogravura aliada a temas modernos (BLAKEMORE, 1975, p. 247).

Salienta-se aqui que a bibliografia sobre gravuras japonesas é escassa e os artistas citados a seguir fazem parte também da autoria de algumas gravuras do acervo, porém

\footnotetext{
${ }^{14}$ Arte que surgiu no final do século XVII, que combina canto e dança. Obra dramática popular convertida em uma arte especificadamente japonesa, onde todos os papéis eram representados por homens. FAHR-BECKER, Gabriele. Grabados Japoneses. Köln: Tashen, 2007. p. 192.

${ }^{15}$ Obra de pintura, desenho ou escultura composta de três partes que formam uma imagem, unidas ou não por uma moldura. PRIBERAN DICIONÁRIO. Tríptico. 2013. Disponível em: $<$ https://www.priberam.pt/dlpo/tr\%C3\%ADptico>. Acesso em: 09 Jan. 2017.
} 
não será discorrido sobre suas características particulares enquanto artistas. São eles: Hachisuka Kiniaki, H. Tanji, H. Tsuji, Hiroshi Kado, Hiroshi Shono, K. Okamura, Kitazuma Arisato, M. Ohka, Takahashi Shouzan, Takashima Chiharu, Yokoyama, Washio Shinryu e, fazendo parte desse grupo de artistas, alguns pescadores como Aida, Harada Hideaki, Minowa e Ueno.

Apesar da escassa bibliografia encontrada é válido explanar sobre o surgimento da gravura, suas principais técnicas e materiais e os artistas mais recorrentes que serão dispostos no subcapítulo a seguir.

\section{Arte e Técnica da Gravura}

A gravura pode ser considerada como a arte de marcar ou a forma de reproduzir imagens e textos sobre uma matriz. Pode-se dizer que ela surgiu na pré-história quando o homem deixa para o mundo seus primeiros registros (FAJARDO; SUSSEKIND; VALE, 1999, p. 11) como apontado na gravura rupestre do Sítio Arqueológico Twyfelfontein na Namíbia (África) - Figura 12.

Caldeira afirma que:

[...] os bens culturais testemunham materialmente a cultura humana e são importantes tanto para o conhecimento da história das civilizações como para que os povos contemporâneos possam ver seu passado refletido nesses objetos e construir sua identidade (CALDEIRA, 2006, p. 91).

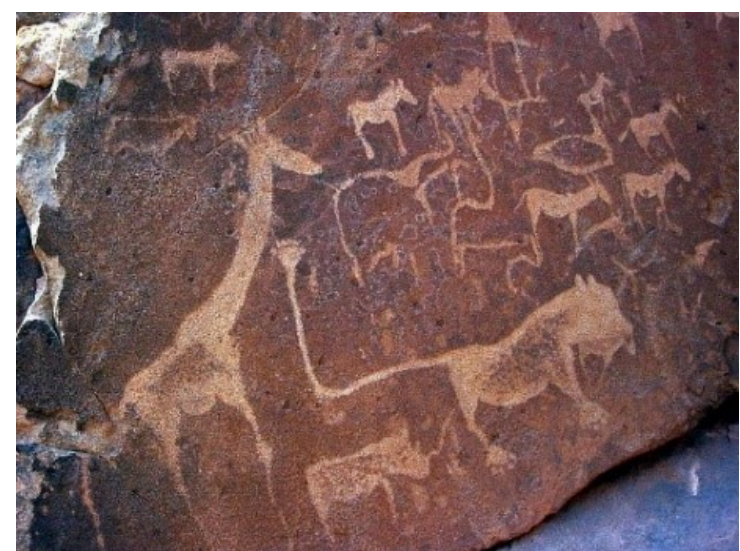

Figura 12 - Gravura rupestre do Sítio Arqueológico Twyfelfontein na Namíbia, África. Fonte: Thomas Schoch, 2011. 
Na China, a gravura em pedra ou madeira com a utilização de uma matriz para impressão é conhecida pelos chineses desde o século II (FAJARDO; SUSSEKIND; VALE, 1999, p.12). Também foram os chineses os criadores do papel artesanal, fabricado com o uso de fibras de bambu e dos arbustos denominados Kozo contendo fibras longas e resistentes, Mitsumata com fibras finas, macias e brilhantes, e Gampi evidenciando fibras estáveis e brilhantes, estando estes representados na Figura 13. Sendo um excelente suporte, o papel, ao longo da história, tornou-se o elemento principal para a reprodução de gravuras, que aliado à posterior invenção da prensa móvel por Johannes Gutenberg por volta de 1450, possibilitou a produção de gravuras em série e o desenvolvimento de variantes das técnicas de reprodução (JORGE; GABRIEL, 1984, p. 14).

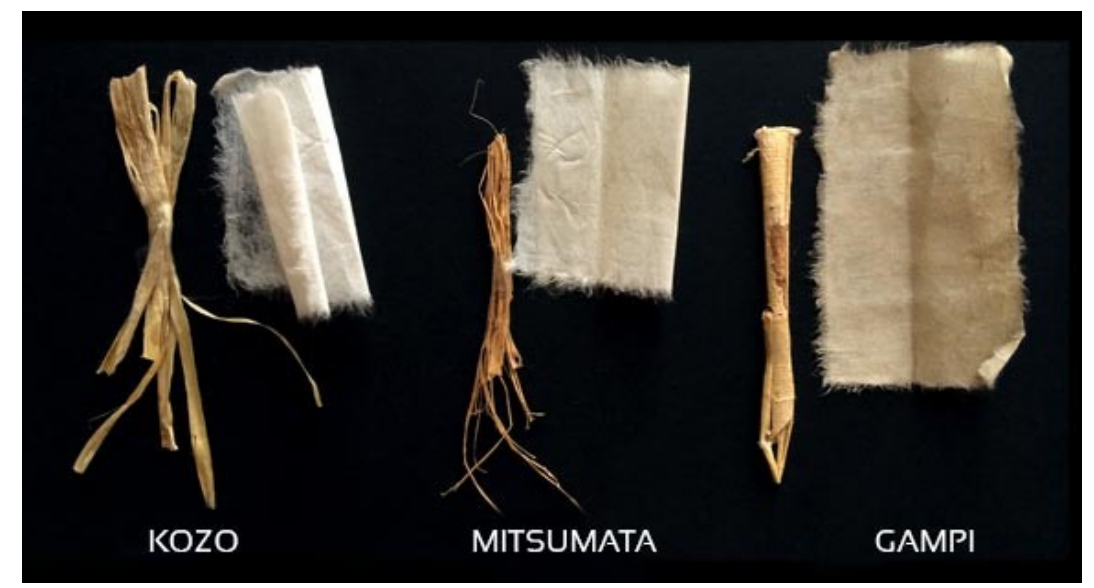

Figura 13 - Fibras dos arbustos de Kozo, Mitsumata e Gampi juntamente com o seu papel originário.

Fonte: Site World Paper Papéis Especiais.

O papel artesanal foi um dos papéis mais utilizados para a reprodução de gravuras, sendo o Japão um dos países que posteriormente adotou a técnica chinesa de fabricação do papel.

Este papel japonês, apresenta diferentes gramaturas, sendo as mais finas comumente utilizadas para a reprodução de xilografias, as de gramatura médias a grossas para a reprodução de litografias, gramaturas grossas para calcografias e para a reprodução de serigrafias independe a gramatura do papel utilizado (WENDT, 2016).

A partir da produção de gravuras em série, iniciou um processo de popularização da técnica, surgindo também vários tipos de impressão e suportes. Estes suportes eram denominados matrizes, sendo a madeira o primeiro a ser utilizado, ficando conhecida a 
técnica como xilogravura. Conforme Kelly Wendt (2016), a xilogravura servia para informar à população acontecimentos do dia-a-dia e ainda não era vista como arte.

A gravura só foi reconhecida como arte quando chegou ao Ocidente, tendo início com as xilogravuras reproduzidas pelo artista Renascentista Dürer no século XV, passando pelas calcogravuras do artista holandês Rembrandt no século XVI e as litogravuras do pintor e gravador espanhol Goya no século XVII. A adaptação da técnica da aquarela à da gravura se deu através das subtécnicas da calcogravura denominadas água-tinta ${ }^{16}$ e maneira negra ${ }^{17}$ desenvolvidas pelo artista Joseph Mallord Willian Turner, no século XVIII (CATAFAL; OLIVA; 2003, p. 15-21).

Em finais do século XIX, os artistas impressionistas Manet, Degas, Gauguin e Henri de Toulouse-Lautrec produziram obras estampadas, denominação também utilizada para as gravuras orientais. $\mathrm{O}$ artista Lautrec destacou-se na litografia à cor influenciado pelos valores da linha e das massas uniformes de cor da gravura oriental (ibid., p. 21).

No século XX, destacam-se os artistas espanhóis Pablo Picasso com a invenção da técnica de reprodução de imagens chamada linóleo-gravura a cor, na qual se podem realizar impressões de várias cores a partir de uma só matriz feita com material sintético, como, por exemplo, a borracha (ibid., p. 47). Além de Picasso, cita-se Joan Miró que fez uso das técnicas da xilografia e calcografia em suas obras. Ainda, o artista americano Andy Warhol fez uso significativo das técnicas da serigrafia que lhe permitiram realizar séries com exemplares numerosos e em consonância com o seu gosto pelos produtos industriais e populares (ibid., p. 23).

No desenvolvimento da matriz de uma gravura, o artista trabalha sobre uma superfície de madeira, pedra ou metal, as quais estão exemplificadas na Figura 14. Após um processo de incisão (riscos ou gravações), está superfície recebe as tintas e faz as impressões, manuais ou prensadas, sendo o material escolhido para a matriz o qual define o tipo de gravura. O resultado das técnicas de impressão é a transferência da imagem da

\footnotetext{
${ }^{16}$ A técnica da Água-Tinta surgiu no século XVII e o seu processo permite a obtenção de valores de cinza a negros profundos, numa chapa de metal, através de uma textura composta por grãos de resina. JORGE, Alice; GABRIEL, Maria. Técnicas da Gravura Artística: Xilografia, Linóleo, Calcografia, Litografia. São Paulo: Ed. Livros Horizonte, 1984. p. 76.

${ }^{17} \mathrm{~A}$ técnica à maneira negra descoberta no século XVII é um processo que consiste no ataque direto sobre o metal, originando uma gravura que parte do negro e passará por todos os valores até chegar ao branco. JORGE; GABRIEL, ibid., p. 56.
} 
matriz para outro tipo de suporte, como papel ou tecido (FAJARDO; SUSSEKIND; VALE, 1999, p. 10). Para se obter um bom resultado, a superfície deve estar bem plana e polida e a dimensão da peça fica a caráter do artista (JORGE; GABRIEL, 1984, p. 25).

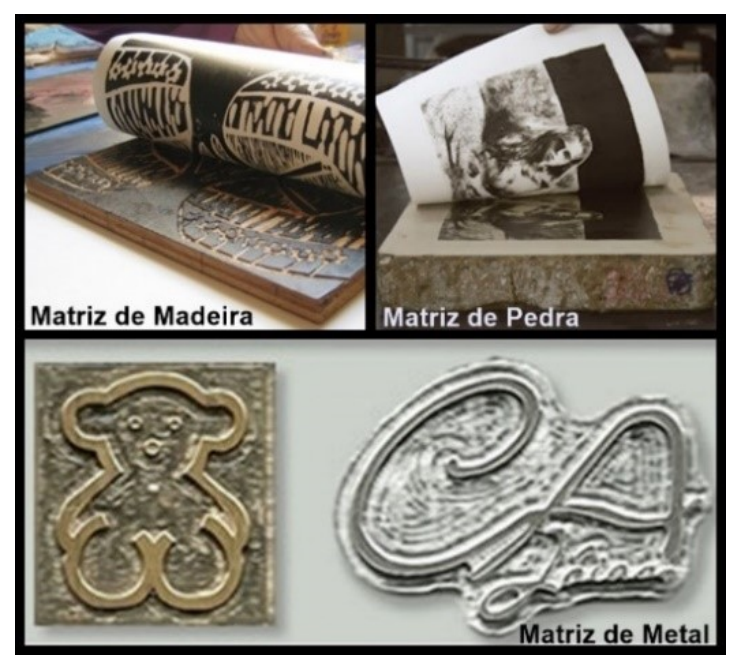

Figura 14 - Superfícies de madeira, pedra e metal utilizadas como matriz. Fonte: Yuuka Makb, 2012.

As gravuras são assinadas, numeradas e datadas pelo próprio artista e em geral aparece no rodapé da gravura, da seguinte forma: 1/100, por exemplo, indicando o número do exemplar (1) e quantas cópias foram produzidas daquela imagem (100) (CATAFAL; OLIVA, 2003, p. 24). Quanto menor for o número do exemplar, mais valorizada é a gravura, pois as primeiras a serem feitas saem de uma matriz menos desgastada. Muitas vezes, as 2 ou 3 primeiras são reservadas para o artista, recebendo a sigla P.A. que significa Prova do Artista (WENDT, 2016).

Apesar de terem surgido na China, foi no Japão, entre o século XVII e o século $\mathrm{XIX}$, que as gravuras orientais começaram a utilizar o suporte madeira como matriz (xilogravura) e se tornaram assim uma arte nacional (JORGE; GABRIEL, 1984, p. 40).

Para a reprodução das gravuras orientais, era necessário o trabalho de três artífices, o pintor, o gravador e o impressor. O pintor criava o desenho, pintava a imagem e seus contornos, e o gravador era quem realizava as incisões na madeira de acordo com o desenho original na posição inversa, enquanto a última etapa era desenvolvida pelo impressor que fazia a tinta da gravura e executava manualmente a sua impressão. 
Sobre os suportes utilizados, as principais madeiras eram as de cerejeira, pereira e tília ${ }^{18}$, sendo o talhe feito no sentido longitudinal da fibra da madeira e suas faces deviam apresentar uma superfície bem lisa e polida para a obtenção de um bom resultado. No caso de gravuras a cores, cada cor era gravada numa madeira separada, na qual, depois de impressa uma primeira prova, o pintor podia verificar as cores ou também deixar escritas as cores a empregar (JORGE; GABRIEL, loc. cit.).

A tinta utilizada era tinta à base de água, feita a partir de pigmentos de cor, misturados com cola de arroz, com a característica de ser transparente, o que permitia a sobreposição de várias cores, apresentando assim a obtenção ilimitada de tons. Este tipo de tinta era aplicado geralmente sobre papel fino e resistente usado para a impressão da matriz. Para a impressão se utilizava um instrumento chamado Baren ${ }^{19}$ que friccionava o papel sobre uma matriz de madeira como indicado na Figura 15 (ibid., p. 41).

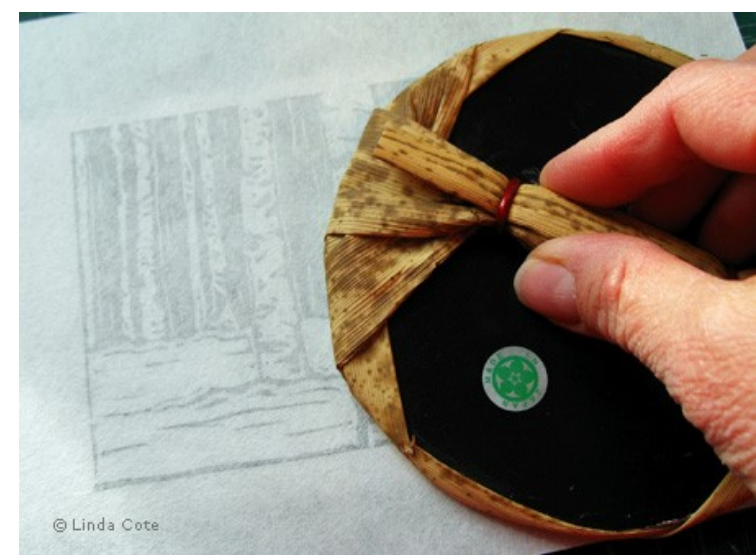

Figura 15 - Instrumento Baren sendo friccionado sobre uma matriz de madeira. Fonte: Linda Cote, 2012.

${ }^{18}$ É um gênero botânico pertencente à família Malvaceae, típica de regiões de clima temperado. Sua textura é fina e uniforme, o fio é reto, o poro fechado e a madeira corta-se bem sem romper. A única desvantagem é não ter praticamente cor nem desenho e amarelecer com a idade. MADEIRAS, José Luis. Ficha técnica: Tília. Portugal: [s.n.]. Disponível em: $<$ http://www.jlm.com.pt/fichastecnicas/FICHATECNICATILIA_PT.pdf $>$. Acesso em: 05 Jan. 2017.

${ }^{19}$ É feito de rodelas de cartão sobrepostas com diâmetro de aproximadamente $13 \mathrm{~cm}$. Estes cartões são recobertos com uma folha de bambu de superfície lisa. As extremidades da folha são enroladas e atadas no lado oposto permitindo, que as mesmas funcionem como punho para agarrar com as mãos e, circular o Baren cuidadosamente sobre o fino papel do Japão. JORGE, Alice; GABRIEL, Maria. Técnicas da Gravura Artística: Xilografia, Linóleo, Calcografia, Litografia. São Paulo: Ed. Livros Horizonte, 1984. p. 41. 
Sobre os gravuristas orientais pioneiros destacam-se: Hishikawa Moronobu que trabalhou com a técnica "Ukiyo-ê" que se refere aos costumes e hábitos de uma sociedade, temas desse mundo passageiro ou pinturas de rua, como também eram chamadas (HERSKOVITAS, 1986, p. 109). Torii Kiyonobu e Nishikawa Sukenobu foram artistas que seguiram a técnica "Sumizuri-ê", técnica de gravura com uso de bloco de madeira que imprimia a linha desenhada em sistema monocromático. A técnica "Benizuri-ê", sistema em três cores foi adotada pelo gravurista Suzuki Harunobu, que a utilizou com cinco cores, surgindo assim, a denominada técnica "Nishiki-ê", gravura de impressão a cor (COSTELLA, op. cit., p. 52).

As gravuras orientais pertencentes ao acervo do MALG encontram-se em processo embrionário de inventário, preenchimento de documentação auxiliar e diagnóstico de conservação. O capítulo a seguir apresenta os resultados da documentação de algumas obras deste acervo, assim como as análises do estado de conservação da coleção de gravuras orientais do Museu de Arte Leopoldo Gotuzzo.

\section{DOCUMENTAÇÃO E ANÁLISE DE CONSERVAÇÃO DA COLEÇÃO DE GRAVURAS ORIENTAIS DO MUSEU DE ARTE LEOPOLDO GOTUZZO}

Por ser um acervo doado recentemente a maioria das obras ainda não foram inventariadas, não sendo possível especificar o número exato de exemplares da coleção.

A proposta inicial era efetuar uma análise do estado de conservação e realizar a documentação de todas as gravuras dessa coleção, mas como o tempo para a pesquisa era restrito e o número de gravuras doadas é muito expressivo, foi necessário realizar um recorte, sendo escolhida para esta pesquisa a coleção de gravuras orientais. Entretanto, em virtude da greve das três categorias ligadas à UFPel, esta não pôde ser desenvolvida na sua totalidade e se deu sobre $75 \%$ do acervo, resultando num total de 306 gravuras analisadas e documentadas.

Para uma melhor organização das informações obtidas através das análises, foi necessário criar um documento que abarcasse todas as particularidades que estas obras possuem e que necessitavam ser documentadas. Sendo assim, as informações extraídas tanto do arquivo do MALG, como da entrevista e consultoria realizas, além da análise visual de cada exemplar com auxílio de lupa e acompanhamento de registro fotográfico, 
serviram para preencher com êxito os campos da ficha de identificação e diagnóstico elaborada pela autora conforme mostra a Figura 16.

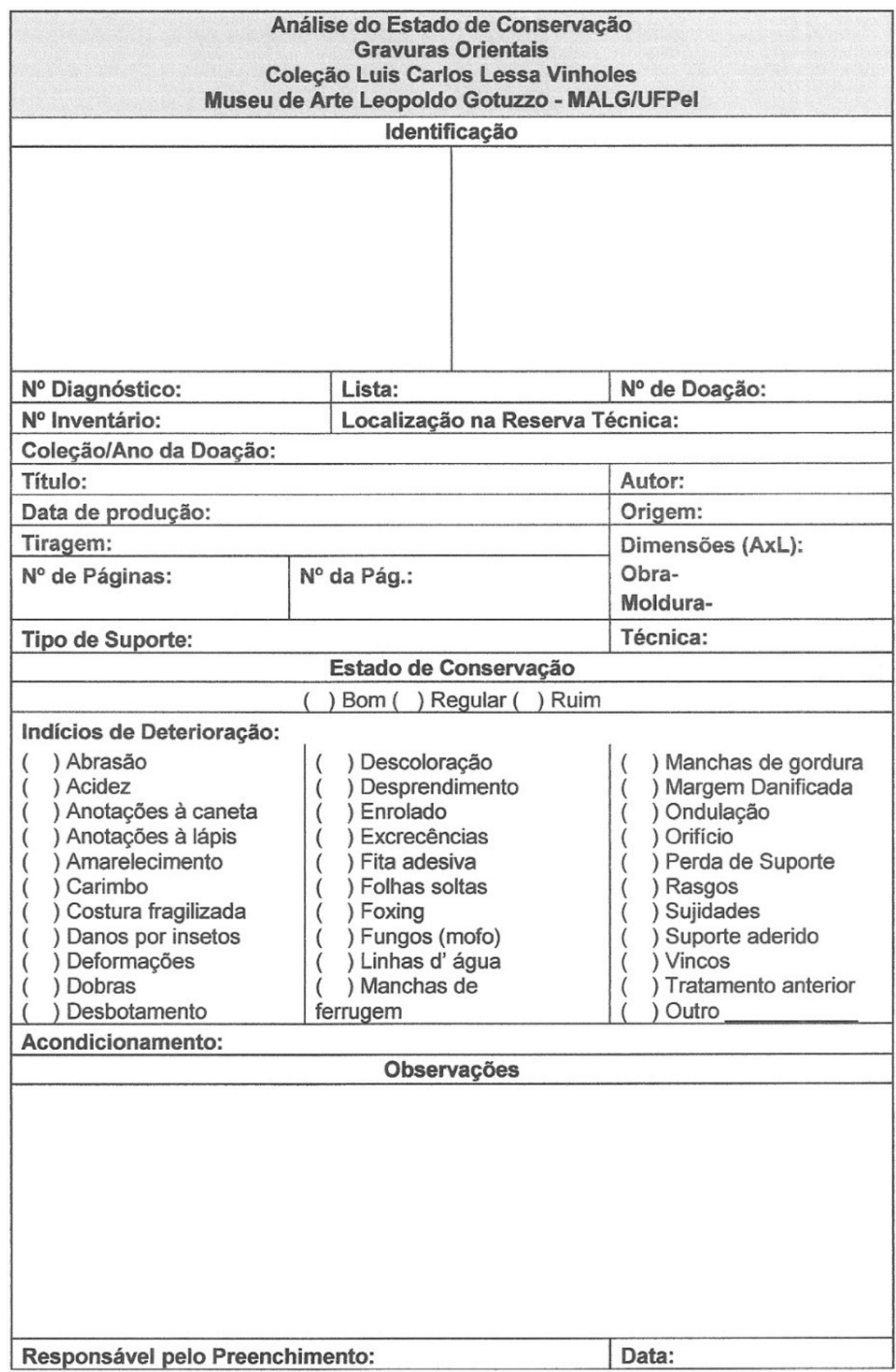

Figura 16 - Modelo da Ficha de Identificação e Diagnóstico realizada pela autora para análise do estado de conservação das gravuras orientais do MALG/UFPel.

Fonte: Elaborada pela autora, 2016. 
A ficha foi elaborada com base em documentos técnicos de algumas instituições de guarda como a Biblioteca Nacional/RJ, o Arquivo Público do Estado de Santa Catarina e o próprio MALG, além do que foi ensinado durante as aulas de documentação do Curso de Conservação e Restauração da UFPel. Optou-se por não utilizar a ficha do MALG porque o acervo possui muitas especificidades e, portanto, havia a necessidade de acrescentar alguns campos na ficha para contemplar estes itens.

Alguns itens da ficha de identificação e diagnóstico criada para esta coleção serão clarificados com intuito de facilitar a leitura do documento em momento posterior a esta pesquisa. O campo número de diagnóstico foi criado para que se tivesse uma organização interna da pesquisa, não tem relação com os itens de número de inventário nem com o número provisório do acervo ou qualquer outro sistema de numeração da instituição.

A ordem estabelecida para organização interna e número de diagnóstico foi uma numeração crescente no campo número de diagnóstico de acordo com as listas de doação fornecidas pela museóloga do museu. É válido salientar que estas listas não são o documento de inventario das obras e, sim uma forma de organização da equipe do MALG que trabalha diretamente com o acervo, na qual constam informações técnicas, como: número de inventario, ano, técnica, tiragem, título, autoria e dimensões da obra, além de indicar a coleção pertencente e o ano de sua doação.

Todas as informações apontadas na ficha de identificação e diagnóstico foram realizadas com base na documentação interna do MALG, relatos do doador da coleção ao museu, consultoria com a especialista em gravuras e conhecimento técnico da proponente desta pesquisa sobre conservação preventiva e análise do estado de conservação de obras com suporte em papel.

A partir da experiência obtida no curso de Conservação e Restauração de Bens Culturais Móveis/UFPel e da revisão bibliográfica sobre conservação e restauração de papel foram criados alguns critérios para facilitar a análise do estado de conservação destas obras.

Os critérios utilizados para definir o estado de conservação das gravuras orientais do MALG foram classificados como Bom, Regular e Ruim, a constar:

BOM: Obras intactas ou que apresentassem pequenas degradações pontuais como amarelecimento, anotações a lápis, excrescências, enrolado, ondulação, sujidades e vincos. A figura 17 é um exemplo de uma obra em bom estado de conservação. 


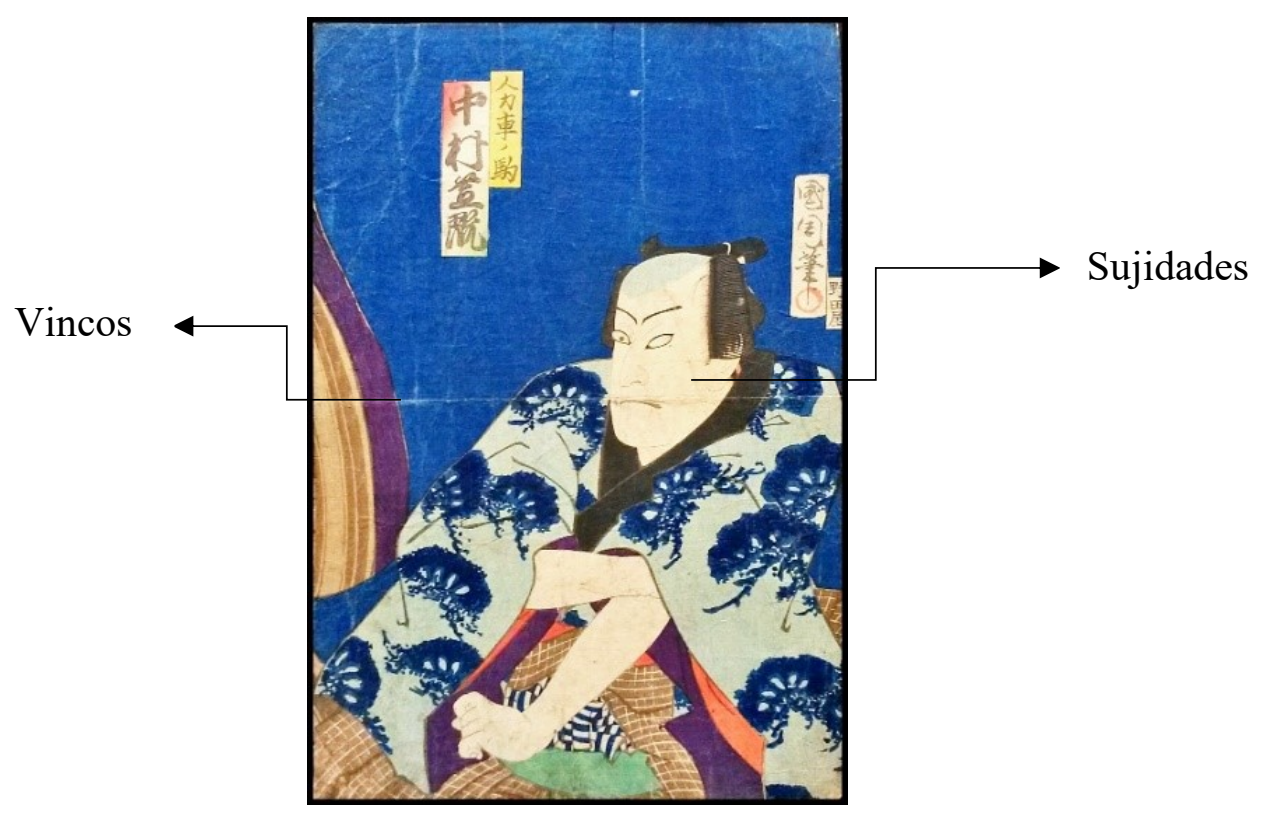

Figura 17 - Exemplo de gravura em bom estado de conservação.

Fonte: Fotografia da autora, 2016.

REGULAR: Obras que contenham além das degradações indicadas no estado bom de conservação, danos como abrasão, acidez, costura fragilizada, deformações, fita adesiva, folhas soltas, manchas de ferrugem ou de gordura, orifícios (figura 18) e margem danificada.

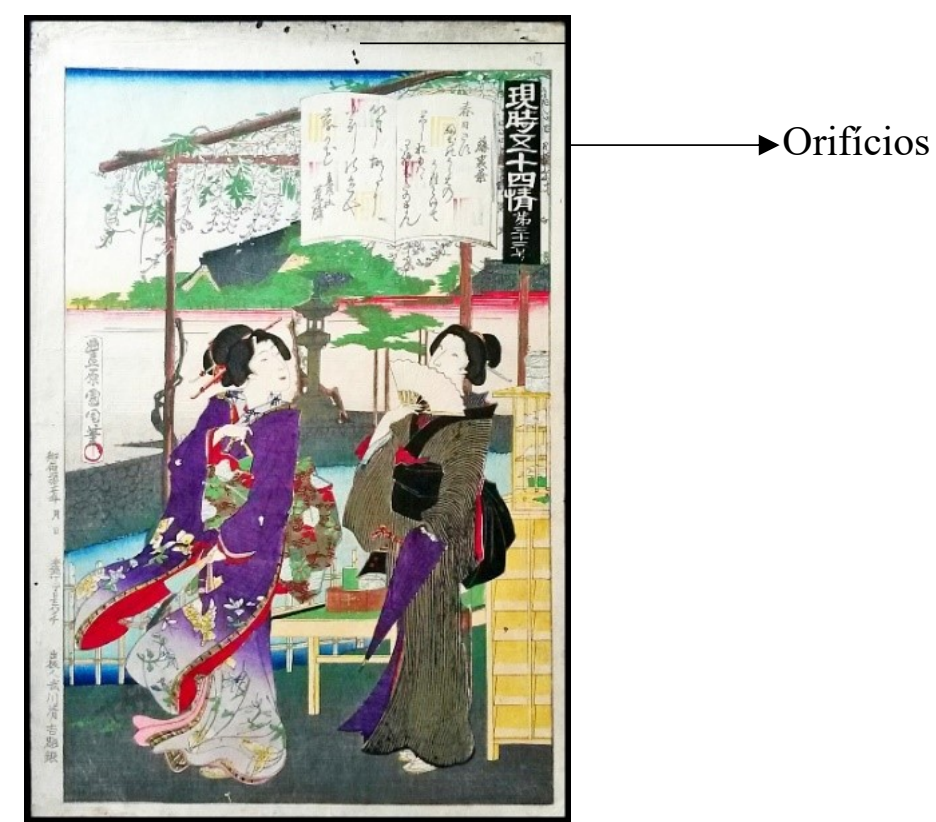

Figura 18 - Exemplo de gravura com estado de conservação regular. Fonte: Fotografia da autora, 2016. 
RUIM: Gravuras que contenham as degradações contidas nos critérios bom e regular e ainda apresentem alguma destas deteriorações: anotações a caneta, carimbo, danos por insetos, desbotamento, descoloração, desprendimento, foxing, fungos, linhas d' água, perda de suporte (figura 19) e rasgos.

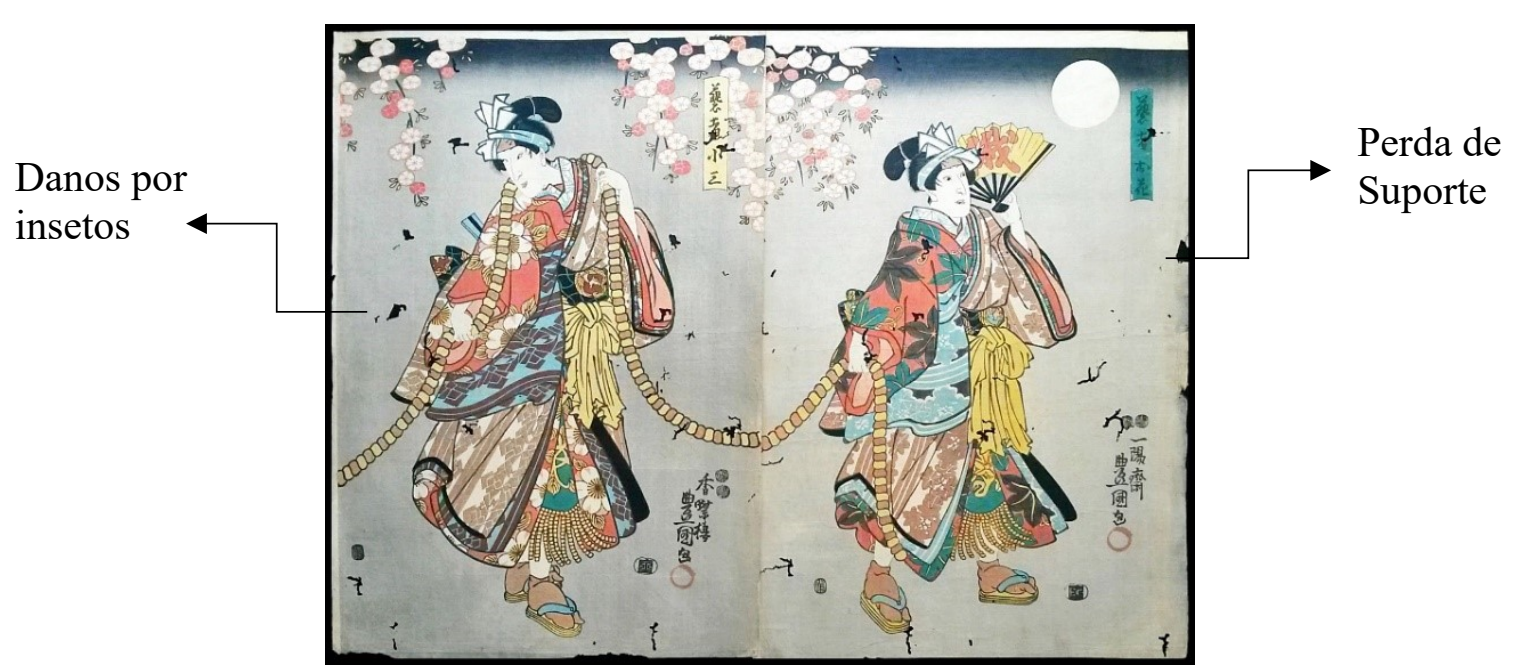

Figura 19 - Exemplo de gravura com estado de conservação ruim. Fonte: Fotografia da autora, 2016.

Em relação aos bens culturais em suporte papel, o conhecimento acerca de suas peculiaridades auxilia na sua classificação, identificação e determinação de eventuais problemas, contribuindo em cada caso na escolha dos procedimentos e materiais adequados ao seu tratamento (PASCUAL, 2006, p. 12). Por ser um material higroscópico, o papel absorve água, sendo muito sensível à umidade/UR, luz e temperatura inadequadas. Estes fatores são elencados como os principais causadores da deterioração das fibras do papel e dos materiais sustentados (pigmentos, tintas, etc.), além de propiciarem a perda de resistência mecânica desses suportes (TEIXEIRA; GHIZONE, 2012, p. 17).

Os 10 agentes de degradação elencados como os principais fatores que contribuem para colocar em risco a segurança e estabilidade de um acervo são: água (inundações); contaminantes (poluição atmosférica); dissociação ${ }^{20}$; forças físicas (impacto, choque,

\footnotetext{
${ }^{20}$ Provoca a perda de objetos, de sua informação relacionada ou da capacidade de recuperar e associar objetos e informação. BRASIL, CENTRO DE DOCUMENTAÇ̃̃O E INFORMAÇÃO (CEDI). Guia de preservação do patrimônio cultural da Câmara dos Deputados. Brasília: Editora Câmara, 2014. p. 19. Disponível em: $<$ file:///E:/Downloads/guia_preservacao_patrimonio.pdf>. Acesso em: 07 Jan. 2017.
} 
vibração, pressão e abrasão); fogo (incêndios); pragas (microrganismos, insetos, roedores, aves e morcegos); roubos e vandalismo; luz, umidade relativa e temperatura inadequadas (MICHALSKI, 2009).

Os resultados obtidos na análise do estado de conservação do acervo mostram que as obras já apresentavam sinais de degradação antes de sua doação ao MALG e estes danos iniciais, fazem com que seja necessário um trabalho de estabilização para "interromper um processo que esteja deteriorando o suporte e/ou seus agregados" (CASSARES; MOI, 2000, p. 25).

Por questões técnicas de conservação durante a realização da análise, 11 gravuras, emolduradas e em bom estado de conservação, não foram retiradas das suas molduras para a análise, representadas aqui pelas gravuras "Poem 71-8" na Figura 20 e "Seat-4" na Figura 21.

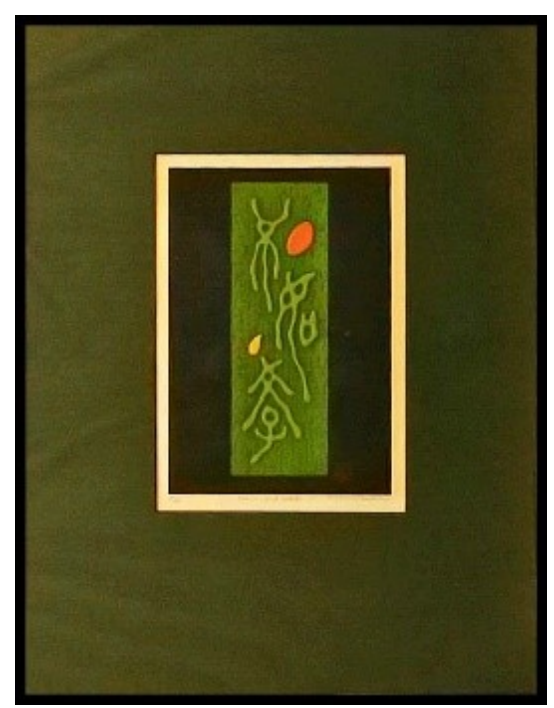

Figura 20 - Gravura emoldurada Poem 71-8 de Haku Maki (1971) em bom estado de conservação.

Fonte: Fotografia da autora, 2016.

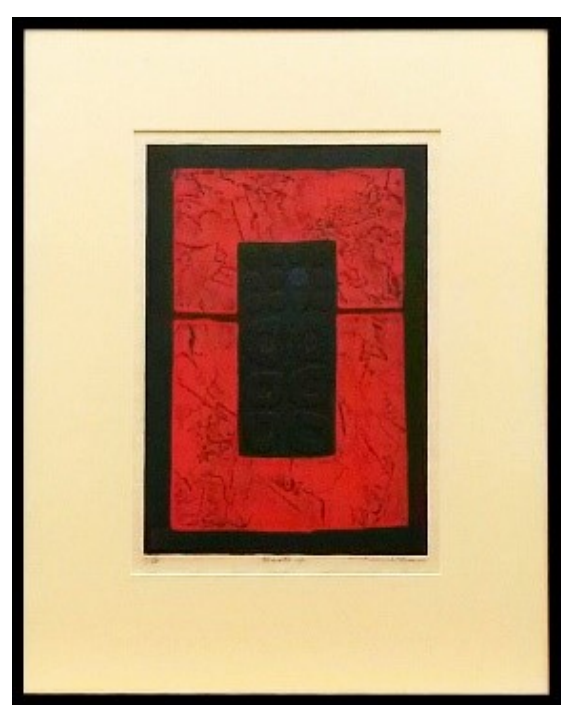

Figura 21 - Gravura emoldurada Seat-4 de Haku Maki (1980) em bom estado de conservação.

Fonte: Fotografia da autora, 2016.

Durante as análises de conservação verificaram-se que grande parte do acervo apresenta amarelecimento, danos causados por insetos, vincos e sujidades. A paisagem "Ukiyo-ê" (figura 22) apresenta danos como amarelecimento e ataque de insetos, enquanto a Figura 23 evidencia, através da gravura com a técnica Gyotaku, outros sinais comuns de deterioração como marcas por terem sido enrolados, vincos e rasgos. Além 
destes danos, encontra-se recorrentemente no acervo abrasão, acidez, desgastes, dobras, fita adesiva, linhas d'água, manchas, ondulação, orifícios, deformações, desbotamento.

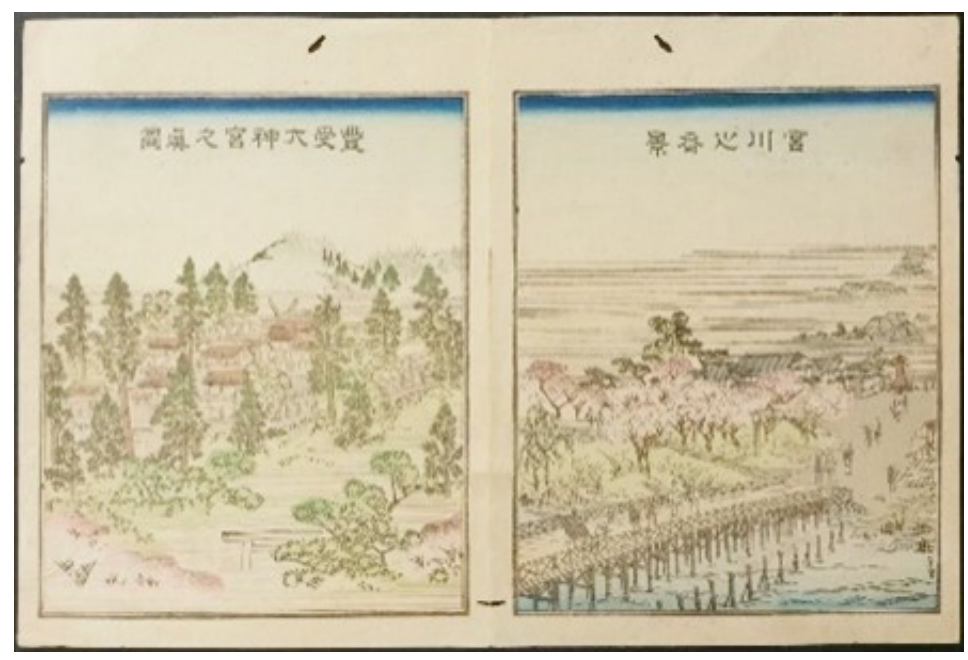

Figura 22 - Gravura de paisagem UKiyo-ê do século XIX, expõe danos como amarelecimento, vincos, danos por insetos e sujidades.

Fonte: Fotografia da autora, 2016.

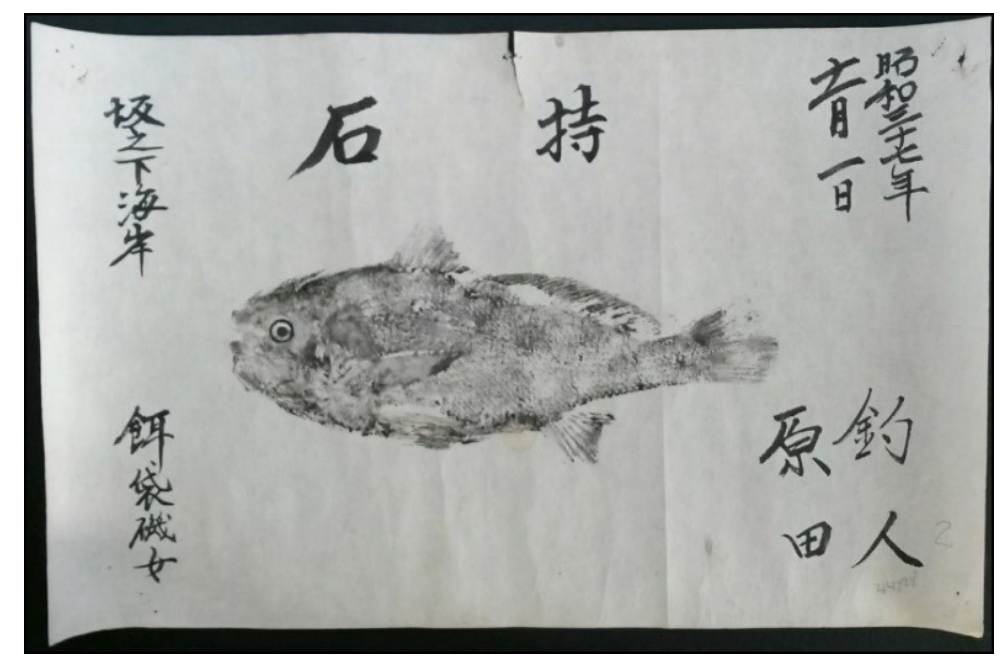

Figura 23 - Gravura da técnica Gyotaku de Harada (1962) apresenta danos como enrolado, vincos, rasgos e sujidades.

Fonte: Fotografia da autora, 2016.

A quantificação geral dos indícios de deterioração encontrados no acervo e anotados individualmente na ficha de identificação e diagnóstico das gravuras estão expostos na tabela a seguir. 


\begin{tabular}{|c|c|c|c|}
\hline \multicolumn{5}{|c|}{ Tabela 01 - Quantificação dos indícios de deterioração da coleção de gravuras } \\
orientais do MALG \\
\hline Abrasão & 27 & Folhas soltas & 0 \\
\hline Acidez & 37 & Foxing & 3 \\
\hline Anotações à caneta & 0 & Fungos & 4 \\
\hline Anotações à lápis & 67 & Linha d' água & 10 \\
\hline Amarelecimento & 301 & $\begin{array}{c}\text { Manchas de } \\
\text { ferrugem }\end{array}$ & 278 \\
\hline Carimbo & 0 & Manchas de & 46 \\
& & gordura & 0 \\
\hline Costura fragilizada & 0 & Margem danificada & 23 \\
\hline Danos por insetos & 53 & Ondulação & 38 \\
\hline Deformações & 161 & Orifício & 36 \\
\hline Dobras & 151 & Perda de suporte & 47 \\
\hline Desbotamento & 100 & Rasgos & 306 \\
\hline Descoloração & 16 & Sujidades & 5 \\
\hline Desprendimento & 1 & Suporte aderido & 162 \\
\hline Enrolado & 32 & Vincos & 12 \\
\hline Excrescências & 225 & Tratamento & anterior \\
\hline Fita adesiva & 19 & Outro & 0 \\
\hline
\end{tabular}

Tabela 01 - Quantificação dos indícios de deterioração da coleção de gravuras orientais do MALG.

Fonte: Elaborada pela autora com base nas fichas de diagnóstico de conservação, 2016.

Durante a análise, verificou-se que as gravuras orientais necessitam de um acondicionamento especializado e, cabe ressaltar, que está sendo executado pela equipe do MALG no andamento dos processos de conservação. Pelo fato do museu apresentar insuficiência de espaço e mobiliário, estes processos acabam tornando-se lentos. Segundo TEIXEIRA; GUIZONE (2013, p. 27), os bens em suporte papel devem ser guardados em mapotecas e acondicionados individualmente com o uso de passe-partout de $\mathrm{pH}$ neutro ou alcalino dependendo do tipo de papel, o qual oferece proteção e facilidade para o manuseio. Também se utilizam pastas apropriadas como as encontradas em livrarias, do tipo polionda, ampliando assim a proteção do acervo (MORELATTO; MANTOVANI; LOVIZIO, 2008, p. 19).

Para manter a reserva técnica do MALG em condições que propiciem a estabilidade do acervo, a equipe da instituição conta com o auxílio de termohigrômetro 
que tem a capacidade de registrar e informar a temperatura e a umidade relativa do ar no ambiente, podendo apresentar a data e o horário do monitoramento (MENDES; RIBEIRO, 2001, p. 72), cujos resultados são anotados diariamente, em turnos alternados, porém, atualmente ele não está sendo utilizado por estar avariado.

O museu conta ainda com desumidificador que tem a capacidade de remoção de água do ar no ambiente (MENDES; RIBEIRO, op. cit., p. 80) e é utilizado somente quando a UR ultrapassa $65 \%$, porém sempre é desligado à noite por questões de segurança, devido às condições instáveis da rede elétrica.

O luxímetro faz a medição da intensidade de luz existente no ambiente (ibid., p. 87) e no MALG é usado como instrumento de monitoramento para adequar a luminescência entre 50 e 80 LUX. Nas atividades diárias, cabe salientar, que a luz da reserva técnica permanece apagada quando não há atividades na sala.

Sobre a ventilação do ambiente, a equipe do museu utiliza o ventilador quando a UR atinge parâmetros em torno de $60 \%$ e a T $25^{\circ} \mathrm{C}$, com intuito de equilibrar os níveis ambientais. Durante essa ação, o ventilador é trocado de posição para que o ar circule por todas as estantes e, contribuindo com essa medida, as portas da reserva técnica também ficam entreabertas para que haja trocas de ar no ambiente. Morelatto; Mantovani; Lovizio (2007, p. 52) afirmam que o controle de T e UR devem ser constantes, pois a variação elevada desses padrões podem causar danos ainda maiores no acervo, como por exemplo, acarretar no lançamento de mais umidade ou calor para o interior da reserva técnica.

Apesar do uso de equipamentos para auxiliar no monitoramento de parâmetros como intensidade de luz, umidade e temperatura no local em que o acervo está acondicionado, o controle também é realizado por observações organolépticas desempenhadas através dos sentidos humanos como calor excessivo, cheiros, modificações significativas das dimensões de obras, dejetos de insetos e animais maiores.

O trabalho de acondicionamento e controle ambiental é definido como ações de conservação preventiva que, na terminologia publicada no Boletim Eletrônico da ABRACOR, é designada como todas as medidas que objetivam evitar ou minimizar futuras deteriorações ou perdas, sendo realizadas no contexto ou na área circundante ao bem, ou mais frequentemente em um grupo de bens. Segundo Callol a prevenção é utilizada para “[...] evitar ou retardar a deterioração, mais das coleções do que dos objetos 
individuais, atendendo todos aqueles aspectos relacionados à deterioração dos acervos, dando ênfase especial aos fatores ambientais" (CALLOL, 2013, p. 18).

Spinelli (1997, p. 13) afirma que, para as instituições conseguirem conservar seu acervo, é preciso que tenham, além de uma administração segura, recursos adequados e que os responsáveis pelo acervo tenham conhecimentos específicos. Neste sentido, aponta-se que a equipe do MALG vem desempenhando um papel importante na conservação e documentação desta coleção de acordo com as suas possibilidades e limitações técnicas. Este trabalho contribui significativamente para a criação de uma documentação extensa sobre a coleção de gravuras orientais do MALG, já que entrega a instituição dados importantes a respeito desse espólio. Ainda assim, afirma-se que não se esgota aqui a necessidade de pesquisa e documentação, já que cada gravura estudada possui uma particularidade que necessita ser apreciada com maior cuidado e dedicação.

\section{CONCLUSÃO}

Nesta pesquisa foram analisadas 306 gravuras que representam, através de sua minuciosa técnica artística, as tradições culturais do Oriente, pertencentes ao início do século XVII e ao final do século XIX. Esta coleção, doada por Luis Carlos Lessa Vinholes, vem sendo inventariada pelo MALG desde 2012. Ainda existem diversas lacunas na documentação dessa coleção, tendo em vista que nem todas as obras foram inventariadas e diagnosticadas.

Os dados expostos na tabela abaixo apresentam o que já foi inventariado, o que ainda está com número provisório e o que ainda não foi inventariado de acordo com as 306 gravuras orientais analisadas nessa pesquisa.

\begin{tabular}{|c|c|}
\hline $\begin{array}{c}\text { Tabela 02 - Quantificação em relação ao inventário da coleção de gravuras } \\
\text { orientais do MALG }\end{array}$ \\
\hline Gravuras inventariadas & 202 \\
\hline Gravuras com $n^{\circ}$ provisório & 35 \\
\hline Gravuras não inventariadas & 69 \\
\hline
\end{tabular}

Tabela 02 - Quantificação em relação ao inventário da coleção de gravuras orientais do MALG.

Fonte: Elaborada pela autora com base nas fichas de diagnóstico de conservação, 2016. 
Este trabalho buscou contribuir com a produção de documentação sobre a coleção de gravuras orientais da instituição, através da realização de entrevistas com o doador da coleção, consultoria técnica com uma especialista em gravuras e criação de fichas de identificação e diagnóstico que compilaram as informações disponíveis sobre as gravuras, no arquivo do MALG e na bibliografia especializada.

Neste sentido, ressalta-se escassez de bibliografia acerca de gravuras orientais, fator que dificultou a identificação de parte do acervo durante esta pesquisa. Como resultados desta pesquisa, verificou-se que a maioria das gravuras foi impressa em papel artesanal japonês, de diferentes gramaturas. Identificou-se que os papéis de gramatura mais fina foram utilizados para a reprodução de xilografias, as de gramatura médias e grossas para a reprodução de litografias, gramaturas grossas para calcografias, sendo que para as serigrafias independia a gramatura dos papéis. Sobre as cores, destaca-se uso de tons vibrantes como amarelo, azul, verde, vermelho e roxo enquanto a minoria apresenta o preto e branco.

De acordo com os resultados obtidos durante a análise, foi realizada a quantificação do estado de conservação - bom, regular e ruim - das gravuras orientais do MALG através da análise nas fichas de identificação e diagnóstico de cada exemplar. Logo, são apresentados os seguintes dados:

\begin{tabular}{|c|c|}
\hline $\begin{array}{c}\text { Tabela 03- Quantidade de obras classificadas quanto ao seu estado de } \\
\text { conservação }\end{array}$ \\
\hline Bom & 40 \\
\hline Regular & 182 \\
\hline Ruim & 84 \\
\hline
\end{tabular}

Tabela 03- Quantidade de obras classificadas quanto ao seu estado de conservação. Fonte: Elaborada pela autora com base nas fichas de diagnóstico de conservação, 2016.

A partir dos dados acima constata-se que o estado de conservação geral do acervo pode ser considerado como regular e os danos recorrentes são amarelecimento, manchas, dobras, vincos, ataques por insetos, enrolado, rasgos, abrasão, acidez, desgastes, fita adesiva, linhas d'água, ondulação, orifícios, deformações, desbotamento, sendo que muitos destes danos foram ocasionados provavelmente por condições ambientais e acondicionamento inadequados.

Os resultados alcançados auxiliarão na preservação do acervo e contribuirá em seu processo de inventário. Também proporcionará o conhecimento físico do acervo, o 
que permitirá, à equipe da Instituição, desenvolver medidas de conservação preventiva a partir dos dados obtidos nessa pesquisa.

Salienta-se que o estudo da coleção das gravuras orientais do MALG não se esgota neste trabalho, já que se realizou um apanhado geral sobre as suas características físicas, técnicas e de conservação. Diversos outros aspectos que envolvem este acervo necessitam ainda ser estudados, como origem, histórico, características estéticas e semióticas, dentre outros.

Entende-se que esta pesquisa cumpriu com o seu papel enquanto estudo acadêmico, já que contribuiu para a preservação de um importante acervo federal.

\section{REFERÊNCIAS}

ASSOCIAÇÃO BRASILEIRA DE CONSERVADORES-RESTAURADORES DE BENS CULTURAIS (ABRACOR). Terminologia para definir a conservação do patrimônio cultural tangível. Boletim eletrônico da ABRACOR: n.1, jun. 2010. Disponível em: $<$ https://www.google.com.br/webhp? yv=1\&rct=j\#q=Terminologia + para + definir $+\mathrm{a}+$ con serva $\% \mathrm{C} 3 \% \mathrm{~A} 7 \% \mathrm{C} 3 \% \mathrm{~A} 3 \mathrm{o}+\mathrm{do}+$ patrim $\% \mathrm{C} 3 \% \mathrm{~B} 4$ nio + cultural + tang $\% \mathrm{C} 3 \% \mathrm{ADvel}>$. Acesso em: 09 Jan. 2017.

ALBERT, Verena. Manual de História Oral. Rio de Janeiro: Editora da FGV, 2004.

BLAKEMORE, Frances. Quem é quem em impressões japonesas modernas. Nova Iorque e Tóquio: John Weatherhill, 1975.

BRASIL, CENTRO DE DOCUMENTAÇÃO E INFORMAÇÃO (CEDI). Guia de Preservação do Patrimônio Cultural da Câmara dos Deputados. Brasília: Editora Câmara, 2014. $\quad$ p. $19 . \quad$ Disponível em: <file:///E:/Downloads/guia_preservacao_patrimonio.pdf>. Acesso em: 07 Jan. 2017.

CALDEIRA, Cleide Cristina. Conservação Preventiva em Bibliotecas Públicas da Cidade de São Paulo: Estudo de Campo. 2004. Dissertação (Mestrado) - Escola de Comunicações e Artes, Universidade de São Paulo, São Paulo, 2004.

CASSARES, Norma Cianflone; MOI, Cláudia. Como Fazer Conservação Preventiva em Arquivos e Bibliotecas. São Paulo: Arquivo do Estado e Imprensa Oficial, 2000. p. 80. (Projeto Como fazer, v. 5). Disponível em: $<$ http://www.arqsp.org.br/arquivos/oficinas_colecao_como_fazer/cf5.pdf. $>$. Acesso em: 05 Jan. 2016.

CATAFAL, Jordi; OLIVA, Clara. A Gravura. Lisboa: Editorial Estampa, 2003. 
CONCRETISMO. In: ENCICLOPÉDIA Itaú Cultural de Arte Brasileira. São Paulo: [s.n.]. Disponível em: $<$ http://enciclopedia.itaucultural.org.br/termo9594/concretismo $>$. Acesso em: 14 Set. 2016.

Consultoria concedida por WENDT, Kelly., professora do Centro de Artes da Universidade Federal de Pelotas especialista nas técnicas de gravura à PEREIRA, Pamela Pereira de. em 11 Out. 2016, no Museu de Arte Leopoldo Gotuzzo, Rua General Osório, $\mathrm{n}^{\mathrm{o}} 725$, Pelotas, RS.

CONRADO, Agrário. Japão - Era Meiji. Escrita Biblioteca Virtual de Escritores. São Paulo: Komedi, 2016. Disponível em: $<$ http://www.escrita.com.br/leitura.asp?Texto_ID=10697>. Acesso em: 20 Dez. 2016.

COSTELLA, Antonio. Introdução à Gravura e História da Xilografia. Campos do Jordão: Ed. Mantiqueira, 1984.

COTE, Lucia. Reflexões do Estúdio: Um olhar dentro dos processos criativos da artista Linda Cote. 2012. Disponível em: $<$ https://lindacotestudio.wordpress.com/2012/09/09/wrestling-with-a-print-and winning/>. Acesso em: 05 Jan. 2017.

CLAVAÍN, Javier Tacón. La restauración en Libros y Documentos: Técnicas de Intervención. Madrid: Ollero y Ramos, 2009.

CRAIG, James. Produção Gráfica. São Paulo: Editora NOBEL, 1987.

DICIONÁRIO ONLINE DE PORTUGUÊS - DICIO. Opúsculo. Disponível em: $<$ https://www.dicio.com.br/opusculo/>. Acessado em: 03 Jan. 2017.

Entrevista concedida por VINHOLES, Luis Carlos Lessa., doador da coleção de gravuras à PEREIRA, Pamela Pereira de. em 19 Set. 2016 no Museu de Arte Leopoldo Gotuzzo, Rua General Osório, $n^{0}$ 725, Pelotas, RS.

FAJARDO, Elias; SUSSEKIND, Felipe; VALE, Marcio do. Oficina de Gravura 7. Rio de Janeiro: Ed. Senac Nacional, 1999.

FAHR-BECKER, Gabriele. Grabados Japoneses. Köln: Tashen, 2007.

FARIA, Caroline. Período Edo. Info Escola - Navegando e Aprendendo. Disponível em: $<$ http://www.infoescola.com/japao/periodo-edo/>. Acesso em: 20 Dez. 2016.

FRONER, Yacy-Ara. Reserva técnica. Belo Horizonte: LACICOR-EBA-UFMG, 2008. 24 p. (Tópicos em conservação preventiva; v. 8). Disponível em: $<$ http://www.lacicor.org/demu/pdf/caderno8.pdf $>$. Acesso em: 05 Jan. 2017.

GÓMES, Maria Luisa. La Restauración Examen Científico Aplicado a la Conservación de Obras de Arte. 5ª Edición. Madrid: Ediciones Cátedra, 2008. 
HERSKOVITAS, Anico. Arte e Técnica: Xilogravura. Porto Alegre: Editora Tchê, 1986.

JORGE, Alice; GABRIEL, Maria. Técnicas da Gravura Artística: Xilografia, Linóleo, Calcografia, Litografia. São Paulo: Ed. Livros Horizonte, 1984.

JOVCHELOVITCH, Sandra e BAUER, Martin, Entrevista Narrativa. In BAUER, Martin W. GASKELL, G. Pesquisa Qualitativa com Texto, Imagem e Som: Um Manual Prático. Petrópolis: Vozes, 2008.

KANAAN, Helena (org.). Manual de Gravura. Pelotas: Editora e Gráfica Universitária/UFPEL, 2004.

LACERDA, Claudia Fontoura. História da Conservação e Restauro: Estudo sobre o Restauro das Obras de Leopoldo Gotuzzo na Década de 80 em Pelotas, RS. 2013. 102 fs. Monografia (graduação) Curso de Bacharelado em Conservação e Restauro de Bens Culturais Móveis. Universidade Federal de Pelotas. Disponível em: $<$ https://conservacaoerestauro.files.wordpress.com/2013/05/tcc-claudiafontouralacerda.pdf $>$. Acesso em: 20 Dez. 2016.

MADEIRAS, José Luis. Ficha técnica: Tília. Portugal: [s.n.]. Disponível em: $<$ http://www.jlm.com.pt/fichastecnicas/FICHATECNICATILIA_PT.pdf $>$. Acesso em: 05 Jan. 2017.

MAKB, Yuuka. Gravura. 2012. Disponível em: $<$ https://yuukamkb.wordpress.com/2012/03/>. Acesso em: 05 Jan. 2017.

MENDES, Marylka (org.). [et al]; RIBEIRO, Vera L. (trad.). Conservação: Conceitos e Práticas. Rio de Janeiro: Editora UFRJ, 2001.

MICHALSKI, Stefan. Luz visível, Radiação Ultravioleta e Infravermelha. Canadá: Instituto de Conservação do Canadá, 2009.

MORELATTO, Andréa Bruscagin; MANTOVANI, Nilza da Silva; LOVIZIO, Sandra Maria. Preservação e Conservação. São Paulo: Centro Cultural São Paulo, 2007. (Cadernos de Pesquisa, v. 14). Disponível em: $<$ http://docs 13.minhateca.com.br/734238609,BR,0,0,Preserva\%C3\%A7\%C3\%A3o-e Conserva\%C3\%A7\%C3\%A3o.pdf>. Acesso em: 06 Jan. 2017.

OGDEN, Sherelyn. Armazenagem e Manuseio. 2.ed. Rio de Janeiro: Projeto Conservação Preventiva em Bibliotecas e Arquivos: Arquivo Nacional, 2001. Disponível em: $<$ http://www.portalan.arquivonacional.gov.br/media/CPBA $\% 201 \% 20 \mathrm{a} \% 209 \% 20 \mathrm{Ar}$ mazenamento.pdf $>$. Acesso em: 08 Jan. 2017.

PASCUAL, Eva. Conservar e Restaurar Papel. Lisboa: Editorial Estampa, 2006. 
PORTO, Julián Pérez; GARDEY, Ana. Definición de Tinta del China. In: Definición.de, 2014 Disponível em: <http://definicion.de/tinta-china/>. Acesso em: 03 Jan. 2017.

PRADO, M. Y. de A. A poética da Canção Brasileira. 2009. 138f. Tese de doutorado apresentada ao Departamento de Música da Escola de Comunicações e Artes da Universidade de São Paulo, Ribeirão Preto, 2009.

PRIBERAN DICIONÁRIO. Tríptico. 2013. Disponível em: $<$ https://www.priberam.pt/dlpo/tr\%C3\%ADptico>. Acesso em: 09 Jan. 2016.

SCHOCH, Thomas. Gravuras Rupestres. 2011. Disponível em: $<$ http://mochila-ascostas.blogspot.com.br/2011/08/gravuras-rupestres.html>. Acesso em: 05 Jan. 2017.

SHINKOKAI, Kokusai Bunka. Catálogo Japão na 9a Bienal de São Paulo. São Paulo: Sociedade para as Relações Culturais Internacionais, 1967.

SPINELLI JR., Jayme. A Conservação de Acervos Bibliográficos \& Documentais. Rio de Janeiro: Fundação Biblioteca Nacional, Dep. De Processos Técnicos, 1997. (Documentos técnicos; v. 1). Disponível em: $<$ http://consorcio.bn.br/consorcio/manuais/manualconservacao/manualjame.pdf $>$. Acesso em: 09 Jan. 2017.

STRANG, Tom; KIGAWA, Rika. Combatendo as pragas do patrimônio cultural. Canadá: Instituto de Conservação do Canadá, 2009.

TEIXEIRA, Lia Canola; GHIZONI, Vanilde Rohling. Conservação Preventiva de Acervos. Florianópolis: FCC, 2012. (Coleção Estudos Museológicos, v. 1). Disponível em: $<$ http://www.fcc.sc.gov.br/patrimoniocultural/arquivosSGC/DOWN_151904Conser vacao_Preventiva_1.pdf $>$. Acesso em: 05 Jan. 2016.

TRETIAK, Dan. Haku Maki Catálogo Raisonné, um trabalho em progresso. Pequin: [s.n.], 2016. Disponível em: <http://haku-maki.com/>. Acesso em: 06 Jan. 2016.

UPJOHN, Everard Miller; WINGERT, Paul S.; MAHLER, Jane Gaston. História Mundial da Arte. 6 v. São Paulo: Difel, 1975.

VIÑAS, Salvador Muñoz. La Restauración del Papel. Madri: Editorial Tecnos (Grupo Anaya, S.A.), 2010.

VINHOLES, Luis Carlos Lessa. 2012. Arquivo do Museu de Arte Leopoldo Gotuzzo/MALG. Universidade Federal de Pelotas/UFPel.

. 2014. Arquivo do Museu de Arte Leopoldo

Gotuzzo/MALG. Universidade Federal de Pelotas/UFPel.

2016. Arquivo do Museu de Arte Leopoldo

Gotuzzo/MALG. Universidade Federal de Pelotas/UFPel. 
WORLD PAPER PAPÉIS ESPECIAIS. O Papel Japonês Washi. São Paulo: [s.n.]. Disponível em: <http://www.worldpaper.com.br/washi/>. Acesso em: 05 Jan. 2017. 